\title{
Foreign Body Removal from Left Atrium following Successful PTMC - A Case Report
}

\author{
M Ullah, AAS Majumder, Z Rahman \\ Department of Cardiology, NICVD, Dhaka.
}

\author{
Keywords: \\ Foreign body \\ removal, \\ PTMC, \\ Snare
}

\begin{abstract}
:
With the advent of new technology and hardware. Percutaneous transluminal Mitral Commissurotomy (PTMC) is a safe procedure now-a-days. But it is still a costly procedure for the patients of develops countries like Bangladesh. So, the balloon and hardware is still practiced in some countries. One of the possible but rare complication of reuse in trained cover of the guide wire. We are reporting a case of retained cover of guide wire in LA during PTMC. It was successfully renounced wing a name.
\end{abstract}

(Cardiovasc. j. 2010; 3(1) : 85-88)

\section{Introduction:}

Retained cover of the tip of guidewire in Left Atrium (LA) is a rare complication of PTMC. Foreign body like this in LA may lead to thromboembolism in systemic circulation. Removal of foreign body from LA is also a difficult task.

\section{Case report:}

Mrs X, 21 yrs aged housewife was admitted in NICVD with history of palpitation and shortness of breath on exertion for two years. On clinical examination, she had features consistent with

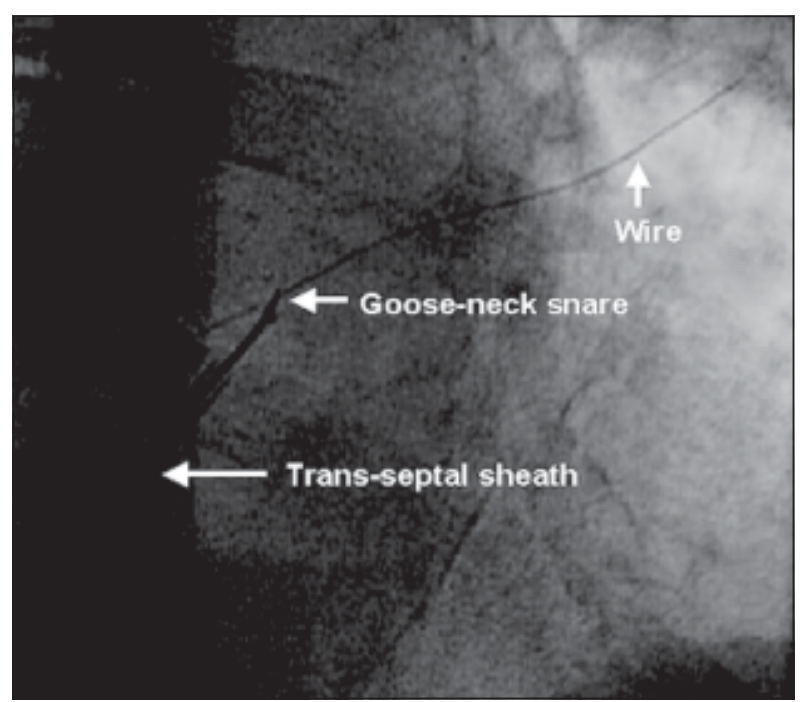

Fig.-1: Left over guidewire in the Left atrium.
'Mitral stenosis with Pulmonary Hypertension'. Echocardiographic evaluation showed that she had 'Severe Mitral stenosis with moderate Pulmonary Hypertension'. Wilkin's score was six. We decided to treat the patient with 'Percutaneous

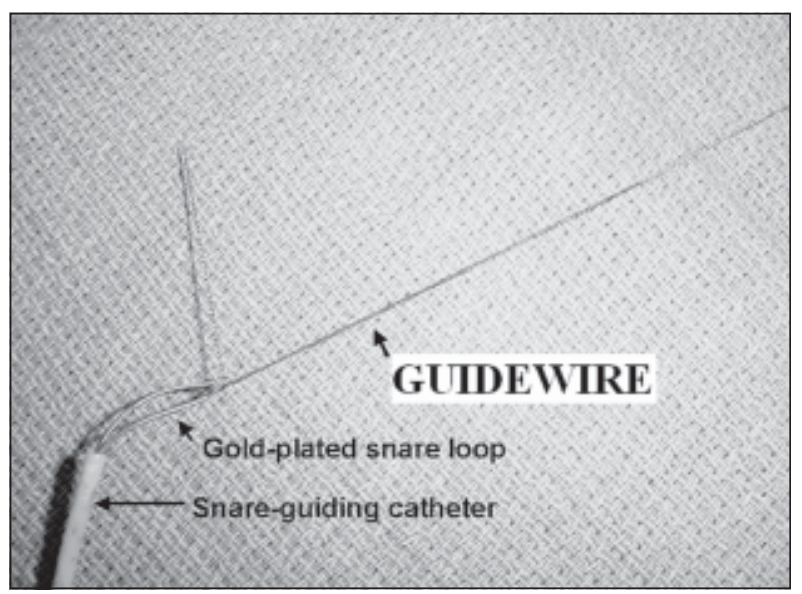

Fig.-2: Guidewire removed with a snare

Transluminal Mitral commissurotomy (PTMC)'. Balloon valvuloplasty was done by trans-septal approach using a 'reused balloon and accessories'. During the procedure everything went smoothly. After removal of balloon from the Left Atrium (LA), it was noticed that a linear structure was left behind in LA. After searching it was found that covering of the terminal coil portion of the PTMC guidewire was missing. A trans-septal puncture

Address of Correspondence : Dr. Mohammad Ullah, Department of Cardiology, NICVD, Dhaka, email: dr_firoze_fcps@yahoo.com 
was done again and an Amplatz Nitinol Goose Neck Snare (Ev3, Plymouth, Minn., USA) was introduced in the LA. The foreign body in the LA was removed by the snare. Patient was hemodynamically stable during and after the procedure. She left hospital three days after the procedure without any complication.

\section{Discussion:}

Common complications of PTMC are - mitral regurgitation, cardiac tamponade due to injury to right or left atrium or left ventricle, infection, thromboembolism and vascular access complications. $^{1}$

Fracture of the cover of Spring wire and its retention in left atrium is not reported any of the literatures searched through Medline. To the best of our knowledge, this is the first case report with this complication.

In our case we used the reused balloon and accessories. In a developing country like Bangladesh, most of the patients who present with chronic rheumatic heart disease with mitral stenosis are from the low socioeconomic condition. And the price of PTMC balloon is high for them. So we sometimes reuse the balloons and accessories. In case of reuse of these catheters and wires, there is possibility of fracture, infection and thromboembolism.

The practice of non-surgical retrieval of intravascular foreign bodies has evolved significantly since the first successful case described in $1964 .^{2}$

Intracardiac and intravascular foreign body can be removed by different methods; like entangling, snaring, and grabbing by use of a loop snare, a helical basket (Dormia basket), hooked guidewires, Fogarty balloon catheters, or a myocardial biopsy foreps.

Foreign body can be entangled and removed with a soft, standard catheter such as a preformed or pigtail catheter by hooking the end of one of these catheters around some portion of the foreign body to dislodge or move it, followed by gentle retraction and removal. The pitfall with this technique is that the foreign body could dislodge and embolize during removal; therefore, a tighter grip on the object, as in the snaring method, is preferable.
The snare technique is used most commonly. It entails passing a loop of exchange length guidewire into a catheter. The snare is advanced with an open loop adjacent to the tip of the catheter. The snare is closed by advancing the catheter over the guidewire ends as soon as the foreign body is caught and it is then slowly removed. ${ }^{3}$ The snare of different sizes is commercially available, and it can also be prepared by using Multipurpose catheter and exchange length PTCA guidewire.

Commercially available snare devices such as the Amplatz Nitinol Goose Neck Snare (Ev3, Plymouth, Minn., USA) have proved to be easy and safe in usage, resulting in high success and low complication rates. ${ }^{4,5,6}$ Disadvantages are high costs and low rate of usage, which make stock keeping of different snare sizes highly inefficient. The cost of the Amplatz Goose Neck Snare is approximately $\$ 250$, while the cost of the self-made wire snare is approximately $\$ 25$ (catheter \& guidewire). ${ }^{7}$

According to some author's experience, the commercially available devices are more difficult to manipulate. The multipurpose catheter allows for good torque control and easy manipulation of the system. ${ }^{8}$

Another technique is to grasp the foreign body directly with a biopsy instrument such as that used for endomyocardial biopsy forceps (Bioptome). This allows retrieval of a foreign body that does not have a readily free end by grasping it at any point. Sometimes a catheter that has been in place for a long time (e.g., a pacemaker lead) can be released in this way. Small pieces of tissue near the lead can be removed to free it with the forceps. This should be done with great caution, only in the ventricle and after other methods have failed, in order to avoid perforation. ${ }^{3}$ The forceps are generally very traumatic because of their rigid structure and inherent difficulties during introduction and advancement. ${ }^{9-11}$

Dormia basket can be used to remove foreign bodies from the heart. A recent study on the use of the Dormia basket in 26 cases reported a success rate of $96 \%$ with no acute or long-term complications. ${ }^{12}$ However; these devices also have some frustrating limitations. Since they cannot be guided, their manipulation is very difficult especially in larger caliper vessels such as the venae cavae. ${ }^{11}$ 
Removal of infected intracardiac pacemaker electrodes and catheter remnants was achieved by cardiotomy in a study, with a mortality rate as high as $10 \%$. For the vast majority of cases, percutaneous techniques have been highly successful and widely utilized in the retrieval of intracardiac foreign bodies. ${ }^{3}$

Of all, the most commonly utilized technique, which was first described by Curry ${ }^{13}$ in 1969 , involves utilization of a snare loop wire. Many variations of this technique have been developed based on different shape and nature of the foreign bodies. Although it is the most commonly used device and is still considered to be the safest, this procedure is often difficult and consumes considerable time. ${ }^{13-}$ 18 The attempt to extract a foreign body using a snare loop might fail if the foreign body is located within the cardiac chambers. ${ }^{19}$

However, when there is no specific tool designed for the retrieval procedure, the interventionalist would face the dilemma whether to send the patient to a more risky and traumatic surgical extraction or to try something else using the available equipment providing that the status of the patient is appropriate. Percutaneous extraction procedures for foreign bodies within the circulatory system are quite safe and relatively simple in comparison to surgical options. They should always be attempted preferably with or even without a specifically designed extraction device before alerting the surgical team. ${ }^{19}$

The safety of percutaneous foreign body retrieval has been confirmed. Factors associated with the small percentage of unsuccessful retrieval attempts include fragments totally in the distal pulmonary artery, extravascular lodging sites, chronically implanted fragments, and pacemaker catheter fragments. ${ }^{20}$

The presence of misplaced foreign bodies in the left atrium is nevertheless a rare event. Apart from rare occasions when foreign bodies are directly placed in the left atrium (e.g., left atrial catheters, ${ }^{21}$ atrial septal defect closure devices, ${ }^{22}$ )the presence of a foreign body in the left atrium invariably requires paradoxical embolization of the object from the venous circulation across the atrial septum. In the pediatric population, paradoxical embolization of umbilical catheters and peripherally inserted central venous catheters has been reported in a small number of cases. ${ }^{23-}$ ${ }^{25}$ Percutaneous retrieval of foreign bodies from the left atrium represents a unique challenge to the interventionalist because of the difficulty in accessing the left atrium. The largest series reporting the retrieval of intravascular objects have not included a single case involving a foreign body in the left atrium. ${ }^{26-32}$

The presence of a foreign body in the left atrium represents a sufficient risk to the patient to warrant removal. While it is impossible to quantify this risk given the paucity of previous reports, potential complications included systemic embolization, infection, and local complications within the heart such as left atrial or pulmonary vein perforation, and atrial arrhythmia. ${ }^{33}$

In conclusion, retention of the cover of the terminal coiled portion of spring wire in LA is a rare complication of PTMC. It may happen during reuse of PTMC balloon. And foreign body like this in the LA can be removed successfully by transseptal puncture and using an Amplatz nitinol Goose Neck Snare.

Conflict of Interest - None.

\section{References:}

1. Hung JS, Tuan NQ, Hung PM, Kim MH, Lao KW. Iroue balloone valvuloplasty. In: Saito S, Nguyen TN, Hu D, Grines CL, Palacion I eds. Advanced International Cardiology. 2nd ed. New York. Blackwell Publishing. 2003; 485-522.

2. Thomas J, Sinclair-Smith B, Bloomfield D, Davachi A. Nonsurgical retrieval of a broken segment of steel spring guide from right atrium and inferior vena cava. Circulation 1964;30:106-108.

3. LMVD Akker-Berman, SG Pinzur, AA Ydinalp, M Brezins, M Gellerman, A Elami, N Roguin. Uneventful 25-Year Course of an Intracardiac Intravenous Catheter Fragment in the Right Heart. $J$ Interven Cardiol 2002;15:421-424.

4. Yedlicka JW Jr, Carlson JE, Hunter DW, CastanedaZuniga WR, Amplatz K. Nitinol gooseneck snare for removal of foreign bodies: experimental study and clinical evaluation. Radiology 1991;178:691-3.

5. Egglin TK, Dickey KW, Rosenblatt M, Pollak JS. Retrieval of intravascular foreign bodies: experience in 32 cases. Am J Roentgenol 1995;164:1259-64.

6. Konya A, Choi BG. Comparison of the Texan foreign body retrieval device and the Amplatz goose neck snare in vivo and in vitro. $J$ Vasc Interv Radiol 2006;17: 693-702. 
7. Mallmann CV, Wolf KJ \& Wacker FK. Retrieval of vascular foreign bodies using a self-made wire snare. Acta Radiol 2008;10:1124-28.

8. Bogart DB, Earnest JB and Miller JT. Special feature: Retrieval of intravascular foreign bodies foreign body retrieval using a simple snare device. Cathet Cardiovasc Diagn 1990; 19:248-250.

9. Cekirge S, Weiss JP, Foster RG, Neiman HL, McLean GK. Percutaneous retrieval of foreign bodies: experience with the nitinol Goose Neck snare. J Vasc Interv Radiol 1993;4:805-10.

10. Gabelmann A, Kramer S,Gorich J. Percutaneous retrieval of lost or misplaced intravascular objects. Am J Roentgenol 2001;176:1509-13.

11. Seong CK, Kim YJ, Chung JW, Kim SH, Han JK, Kim HB, et al. Tubular foreign body or stent: safe retrieval or repositioning using the coaxial snare technique. Korean J Radiol 2002;3:30-7.

12. R Sheth, V Someshwar, G Warawdekar. Percutaneous retrieval of misplaced intravascular foreign objects with the Dormia basket: an effective solution. Cardiovasc Intervent Radiol 2007;30:48-53.

13. Curry JL. Recovery of detached intravascular catheter or guide wire fragments. A proposed method. Am $J$ Roentgenol Radium Ther Nucl Med 1969;105:894-6.

14. Dotter CT, Rosch J, Bilbao MK. Transluminal extraction of catheter and guide fragments from the heart and great vessels; 29 collected cases. Am J Roentgenol 1971;111:467-72.

15. Thomas J, Sinclair-Smith B, Bloomfield D, Davachi A. Non-surgical retrieval of a broken segment of steel spring guide from the right atrium and inferior vena cava. Circulation 1964;30:106-8.

16. Fisher RG, Ferreyro R. Evaluation of current techniques for nonsurgical removal of intravascular iatrogenic foreign bodies. Am J Roentgenol 1978;130:541-8.

17. Fjalling M, List AR. Transvascular retrieval of an accidentally ejected tip occluder and wire. Cardiovasc Intervent Radiol 1982;5:34-6.

18. Kadir S, Athanasoulis CA. Percutaneous retrieval of intravascular foreign bodies. In: Athanasoulis CA, Green RE, Pfister RC, Roberson GH, editors. Interventional Radiology. Philadelphia: W. B. Saunders; 1982. p. $379-90$

19. Candemir B, Polat K, Canbay A. Percutaneous extraction of a short, 0.038-inch guide wire retained in the right common iliac artery. Türk Kardiyol Dern $\mathrm{Ar}^{\circ}$ - Arch Turk Soc Cardiol 2008;36(7):479-481.

20. Dato GMA, Arslanian A, Marzio PD, Filosso PL, Ruffini E. Posttraumatic and iatrogenic foreign bodies in the heart: Report of fourteen cases and review of the literature. The Journal of Thoracic and Cardiovascular Surgery 2003;408-14.

21. Yeo TC, Miller FA Jr, Oh JK, Freeman WK. Retained left atrial catheter: an unusual cardiac source of embolism identified by transesophageal echocardiography. J Am Soc Echocardiogr 1998;11:6670 .

22. Peuster M, Boekenkamp R, Kaulitz R, Fink C, Hausdorf G. Transcatheter retrieval and repositioning of an Amplatzer device embolized into the left atrium. Cathet Cardiovasc Intervent 2000; 51:297-300.

23. Massin M, Lombet J, Rigo J. Percutaneous retrieval of broken silastic catheter from the left atrium in a critically Ill premature infant. Cathet Cardiovasc Diagn 1997;42:409-411.

24. Farrell AG, Parikh SR, Darragh RK, Girod DA. Retrieval of "old" foreign bodies from the cardiovascular system in children. Cathet Cardiovasc Diagn 1998;44:212-217.

25. Ruiz CE, Nystrom GA, Butt AI, Zhang HP. Percutaneous retrieval of a broken umbilical catheter from left atrium in a premature newborn. Cathet Cardiovasc Diagn 1995;36:265-268.

26. Cekirge S, Weiss JP, Foster RG, Neiman HL, McLean GK. Percutaneous retrieval of foreign bodies: experience with the nitinol Goose Neck snare. $J$ Vasc Intervent Radiol 1993;4:805-810.

27. Dondelinger RF, Lepoutre B, Kurdziel JC. Percutaneous vascular foreign body retrieval: experience of an 11year period. Eur J Radiol 1991;12:4-10.

28. Dotter CT, Rosch J, Bilbao MK. Transluminal extraction of catheter and guide fragments from the heart and great vessels; 29 collected cases. Am J Roentgenol Radium Ther Nucl Med 1971;111:467-472.

29. Egglin TK, Dickey KW, Rosenblatt M, Pollak JS. Retrieval of intravascular foreign bodies: experience in 32 cases. Am J Roentgenol 1995;164:1259-1264.

30. Gabelmann A, Kramer S, Gorich J. Percutaneous retrieval of lost or misplaced intravascular objects. Am J Roentgenol 2001;176: 1509-1513.

31. Grabenwoeger F, Bardach G, Dock W, Pinterits F. Percutaneous extraction of centrally embolized foreign bodies: a report of 16 cases. Br J Radiol 1988;61:10141018.

32. Yang FS, Ohta I, Chiang HJ, Lin JC, Shih SL, Ma YC. Nonsurgical retrieval of intravascular foreign body: experience of 12 cases. Eur J Radiol 1994;18:1-5.

33. Casserly IP, Goldstein JA, Rogers JH, Lasala JM. Paradoxical Embolization of a Fractured Guidewire: Successful Retrieval From Left Atrium Using a Snare Device. Cathet Cardiovasc Interven 2002;57:34-38. 